Revista Eletrônica de Direito Processual - REDP. Volume 15. Janeiro a Junho de 2015

Periódico Semestral da Pós-Graduação Stricto Sensu em Direito Processual da UERJ.

Patrono: José Carlos Barbosa Moreira. www.redp.com.br ISSN 1982-7636 PP 435-453

\title{
BARGANHA NO PROCESSO PENAL ITALIANO: ANÁLISE CRÍTICA DO PATTEGGIAMENTO E DAS ALTERNATIVAS PROCEDIMENTAIS NA JUSTIÇA CRIMINAL ${ }^{1}$
}

\section{IL PATTEGGIAMENTO NEL PROCESSO PENALE ITALIANO COME ESPRESSIONE DELLA GIUSTIZIA NEGOZIALE.}

Vinicius Gomes de Vasconcellos Doutorando em Direito na USP. Mestre em Ciências Criminais na PUCRS (2014), bolsista integral CAPES. Pós-graduado em Justiça Penal pela Universidade CastillaLa Mancha (2013). Bacharel em Direito pela PUCRS. Bolsista de Iniciação Científica CNPq/PIBIC (2009/2012). São Paulo/SP.vgomesv@gmail.com

Bruna Capparelli

Doutoranda em Direito Processual Penal na Università degli Studi di Bologna - Alma Mater Studiorum. Qualificada ao exercício da profissão de advogada na Itália. Bolonha, Itália. bruna.capparelli@yahoo.it

RESUMO: Este artigo pretende desenvolver análise descritiva e crítica do modelo negocial previsto no sistema processual penal italiano, com o objetivo de introduzir tal temática de crescente importância no debate jurídico. Embora se mantenha posição contrária à expansão dos espaços negociais, almeja-se verificar possíveis contribuições a um eventual mecanismo de barganha em âmbito brasileiro, conforme propostas em projetos legislativos. Para tanto, inicialmente descrever-se-á brevemente as origens e mudanças ocasionadas no processo penal italiano no início dos anos 90, ressaltando-se as resistências opostas pelos atores do sistema, para então descrever criticamente as possibilidades de procedimentos alternativos introduzidos paulatinamente.

\footnotetext{
${ }^{1}$ Artigo recebido em 23/04/15 e aprovado em 21/06/2015.
} 
Revista Eletrônica de Direito Processual - REDP. Volume 15. Janeiro a Junho de 2015 Periódico Semestral da Pós-Graduação Stricto Sensu em Direito Processual da UERJ. Patrono: José Carlos Barbosa Moreira. www.redp.com.br ISSN 1982-7636 PP 435-453

PALAVRAS-CHAVE: Processo penal italiano. Barganha. Justiça Negocial. Consenso.

Alternativas procedimentais.

RIASSUNTO: Con l'articolo in esame si propone un'analisi descrittiva e critica dei modelli di giustizia negoziale previsti nell'ordinamento italiano, con particolare focus sull'applicazione della pena su richiesta delle parti. L'obiettivo è duplice. In primo luogo si propone una ricostruzione sistematica dell'excursus storico che ha condotto all'introduzione del patteggiamento nel processo penale italiano. In secondo luogo, in un'ottica comparatistica, si intende verificare i limiti di compatibilità di questa disciplina con i principi vigenti nell'ordinamento brasiliano e quali siano i possibili scenari per l'introduzione del summenzionato rito nel rispettivo codice di procedura penale.

PAROLE CHIAVE: Processo penale italiano. Patteggiamento. Giustizia negoziale. Consenso. Procedimenti speciali.

\section{Introdução}

O panorama contemporâneo do processo penal nos mais diversos ordenamentos ocidentais apresenta generalizada tendência em direção à expansão das possibilidades consensuais de imposição de uma sanção penal a partir da aceitação do acusado em troca de um benefício (como a redução da penal), ou seja, sem o desenrolar do devido processo legal em seus termos tradicionais. ${ }^{2}$ No estudo do fenômeno da importação e internacionalização dos mecanismos negociais, por certo, o exemplo da Itália sobressai em importância comparativa. Trata-se de sistema processual que introduziu espaços de consenso em seu ordenamento de modo paulatino até a solidificação de diversos procedimentos alternativos para aceleração de julgamentos, previstos em meio à reforma integral do Código de Processo Penal italiano, marco no cenário mundial em razão de sua pretensão de implementar um modelo acusatório, com inspiração em traços

\footnotetext{
${ }^{2}$ Sobre isso, ver: VASCONCELLOS, Vinicius G. Barganha e Justiça Criminal Negocial: análise das tendências de expansão dos espaços de consenso no processo penal brasileiro. 2014. Dissertação (Mestrado em Ciências Criminais) - Faculdade de Direito, Pontifícia Universidade Católica do Rio Grande do Sul, Porto Alegre.
} 
Revista Eletrônica de Direito Processual - REDP. Volume 15. Janeiro a Junho de 2015 Periódico Semestral da Pós-Graduação Stricto Sensu em Direito Processual da UERJ. Patrono: José Carlos Barbosa Moreira. www.redp.com.br ISSN 1982-7636 PP 435-453 da common law, em um país de origem continental. Nesse sentido, aponta-se que a justiça criminal italiana configurou um instigante "sistema incrustado em meio a duas tradições diferentes", ${ }^{3}$ cuja implementação ocorreu com forte apoio político, ${ }^{4}$ mas resistência no campo jurídico-penal, onde a postura retrospectiva dos atores processuais desvelou a importância das suas atitudes na concretização de reformas legais. ${ }^{5}$

Desse modo, o presente estudo almeja desenvolver análise descritiva e crítica do modelo negocial previsto no sistema processual penal italiano, com o objetivo de introduzir tal temática de crescente importância no debate jurídico. Embora se mantenha posição contrária à expansão dos espaços negociais, almeja-se verificar possíveis contribuições a um eventual mecanismo de barganha em âmbito brasileiro, conforme propostas em projetos legislativos. Para tanto, inicialmente descrever-se-á brevemente as origens e mudanças ocasionadas no processo penal italiano no início dos anos 90, ressaltando-se as resistências opostas pelos atores do sistema, para então descrever criticamente as possibilidades de procedimentos alternativos introduzidos paulatinamente.

\section{Antecedentes autoritários e a reforma processual penal italiana de 1988.}

A reforma processual penal de 1988 revogou a legislação anterior, datada de 1930 e conhecida como "Código Rocco", 6 que se caracterizava por forte influência francesa, enfatizando o controle da criminalidade acima dos direitos do acusado em tons

\footnotetext{
3 MARAFIOTI, Luca. Italian Criminal Procedure: a system caught between two traditions. In: JACKSON, John; LANGER, Máximo; TILLERS, Peter (eds.). Crime, Procedure and Evidence in a Comparative and International Context. Essays in honour of professor Mirjan Damaška. Oxford: Hart Publishing, 2008. p. 91 (tradução livre).

4 LANGER, Máximo. From Legal Transplants to Legal Translations: The Globalization of Plea Bargaining and the Americanization Thesis in Criminal Procedure. In: THAMAN, Stephen C. (ed.). World Plea Bargaining. Consensual Procedures and the Avoidance of the Full Criminal Trial. Durham: Carolina Academic Press, 2010. p. 62.

5 “A história do código não pode ser vista somente como uma disputa entre diferentes ideologias do processo penal, mas também como um exemplo da noção de que, para que uma lei acarrete as consequências esperadas, uma certa aceitação daqueles que irão aplicá-la é necessária." (PANZAVOLTA, Michele. Reforms and Counter-Reforms in the Italian Struggle for an Accusatorial Criminal Law System. North Carolina Journal of International Law \& Commercial Regulation, vol. 30, n. 3, p. 577-623, 2005. p. 578) (tradução livre).

${ }^{6}$ Cumpre lembrar que o referido Código Rocco, revogado na Itália em 1988, foi referência no desenvolvimento do atual Código de Processo Penal brasileiro, o qual reproduziu em termos as críticas acima referidas.
} 
Revista Eletrônica de Direito Processual - REDP. Volume 15. Janeiro a Junho de 2015 Periódico Semestral da Pós-Graduação Stricto Sensu em Direito Processual da UERJ. Patrono: José Carlos Barbosa Moreira. www.redp.com.br ISSN 1982-7636 PP 435-453 inquisitivos. $^{7}$ De modo semelhante ao Código Napoleônico, referência do sistema processual denominado misto, o modelo italiano previa o processo dividido em duas fases, uma investigativa e outra de julgamento, mas não determinava sua separação plena, de modo que os atos praticados no primeiro momento também podiam fundamentar a decisão condenatória do julgador. ${ }^{8}$ Assim, além de fomentar a busca do juiz pela verdade por meio de poderes instrutórios de ofício, tal regramento tornava a etapa judicial mera reprodução e confirmação formal daquilo já produzido anteriormente. $^{9}$

Conforme Giulio Illuminati, desde a década de 60, um novo Código de Processo Penal era preferivel pela Constituição italiana, que, embora implicitamente, determinou a adoção do modelo acusatório. ${ }^{10}$ Somente em 1988, após outras tentativas malsucedidas, foi aprovado o projeto de reforma integral, desenvolvido por comissão de juristas, a partir das diretrizes redigidas pelo legislativo na delegação de tal lei. ${ }^{11}$ Assim, promulgou-se a nova legislação, que, em razão de sua "ruptura radical com o passado", ${ }^{12}$ foi denominada pela doutrina como "revolucionária". ${ }^{13}$ Aponta-se que as principais características consolidadas são: 1) a oralidade e o contraditório, ${ }^{14}$ pois a decisão judicial passou a poder se embasar somente nas provas apresentadas oralmente

\footnotetext{
${ }^{7}$ VAN CLEAVE, Rachel A. An offer you can't refuse? Punishment without trial in Italy and the United States: the search for truth and an efficient criminal justice system. Emory International Law Review, v. 11, p. 419-469, 1997. p. 421.

8 ILLUMINATI, Giulio. The Frustrated Turn to Adversarial Procedure in Italy (Italian Criminal Procedure Code of 1988). Washington University Global Studies Law Review, vol. 4, p. 567-581, 2005. p. 567.

9 PANZAVOLTA, Michele. Reforms and Counter-Reforms in the Italian Struggle for an Accusatorial Criminal Law System, op. cit., p. 579-581. Ressaltando a prevalência dos atos investigativos na formação do convencimento judicial, ver: MARAFIOTI, Luca. Italian Criminal Procedure: a system caught between two traditions. In: JACKSON, John; LANGER, Máximo; TILLERS, Peter (eds.). Crime, Procedure and Evidence in a Comparative and International Context. Essays in honour of professor Mirjan Damaška. Oxford: Hart Publishing, 2008. p. 82.

10 Conforme Giulio Illuminati, o modelo acusatório era constitucionalmente imposto em razão da proteção aos direitos à defesa, à informação, à presunção de inocência, à imparcialidade do julgador, à separação das funções de acusar e julgar, dentre outros (ILLUMINATI, Giulio. The Frustrated Turn to Adversarial Procedure in Italy, op. cit., p. 570-571).

${ }^{11}$ AMODIO, Enio, Vitórias e derrotas da cultura dos juristas na elaboração do novo código de processo penal. Revista Brasileira de Ciências Criminais, São Paulo, ano 7, n. 25, p. 09-22, jan./mar. 1999. p. 0915.

12 ILLUMINATI, Giulio. El sistema acusatorio en Italia. In: BACHMAIER WINTER, Lorena (coord.). Proceso penal y sistemas acusatorios. Madrid: Marcial Pons, 2008. p. 135. (tradução livre).

13 PANZAVOLTA, Michele. Reforms and Counter-Reforms in the Italian Struggle for an Accusatorial Criminal Law System, op. cit., p. 578; ARMENTA DEU, Teresa. Sistemas procesales penales. La justicia penal en Europa y América. Madrid: Marcial Pons, 2012. p. 170.

${ }^{14}$ FERRAJOLI, Luigi. Direito e Razão. Teoria do Garantismo Penal. 4a ed. São Paulo: RT, 2014. p. 678.
} 
Revista Eletrônica de Direito Processual - REDP. Volume 15. Janeiro a Junho de 2015

Periódico Semestral da Pós-Graduação Stricto Sensu em Direito Processual da UERJ.

Patrono: José Carlos Barbosa Moreira. www.redp.com.br ISSN 1982-7636 PP 435-453

pelas partes durante a fase judicial, o que reafirmou a passividade do julgador, ${ }^{15}$ embora

se tenha mantido certos poderes subsidiários, ${ }^{16}$ e o direito ao confronto pelo exame cruzado $;{ }^{17}$ 2) a publicidade dos julgamentos, ${ }^{18} \mathrm{e}$, principalmente, sendo intitulada como "coração do novo sistema", ${ }^{19}$ 3) a estrita separação entre as fases investigatória e de julgamento, a partir da formação de distintos autos processuais, de modo que o julgador do mérito do caso não tenha contato com qualquer ato preliminar, garantindo, assim, sua imparcialidade. ${ }^{20}$

Diante desse cenário, impõe-se a análise detalhada da marcante inovação referida, que, ao limitar o acesso do julgador ao lastro probatório, rompeu com a tradição continental e relativizou a propagada busca pela verdade substancial no processo penal. ${ }^{21}$ O CPP italiano de 1988 reconheceu aquilo que parece cristalino: para que se respeite efetivamente os princípios do contraditório, da oralidade, da imediação e da imparcialidade, ${ }^{22}$ é necessário que os atos praticados no inquérito policial (investigação preliminar, em termos amplos) se mantenham fora do juízo oral, da fase processual de julgamento, a qual deve ser a sede exclusiva de formação de provas legítimas ao convencimento do juiz. ${ }^{23}$ Para tanto, estruturou-se a separação de dois autos: o primeiro,

\footnotetext{
15 "Havia dois objetivos principais do novo código. Primeiro, a acusação e a defesa deviam ser os principais atores do processo penal. Segundo, a decisão judicial somente pode se fundamentar na prova coletada oralmente durante o julgamento." (PANZAVOLTA, Michele. Reforms and Counter-Reforms in the Italian Struggle for an Accusatorial Criminal Law System, op. cit., p. 586) (tradução livre).

${ }^{16}$ Conforme Michele Pazavolta, os juízes ainda possuem poder subsidiário de propor a produção de provas, seja de ofício ou requisitando às partes, se o lastro probatório for insuficiente para a decisão ao final do processo (PANZAVOLTA, Michele. Reforms and Counter-Reforms in the Italian Struggle for an Accusatorial Criminal Law System, op. cit., p. 591). Contudo, a autora critica tal exceção, afirmando que a passividade do juiz deveria ser assegurada para garantir sua imparcialidade (ibidem, p. 623).

${ }^{17}$ LANGER, Máximo. From Legal Transplants to Legal Translations, op cit., p. 61.

${ }^{18}$ VAN CLEAVE, Rachel A. An offer you can't refuse?, op. cit., p. 422.

${ }^{19}$ PANZAVOLTA, Michele. Reforms and Counter-Reforms in the Italian Struggle for an Accusatorial Criminal Law System, op. cit., p. 586.

${ }^{20}$ ILLUMINATI, Giulio. El sistema acusatorio en Italia, op. cit., p. 152-153.

${ }^{21}$ Sobre os contornos da busca pela verdade e os modelos processuais, ver: GRANDE, Elisabetta. Dances of Criminal Justice: thoughts on systemic diferences and the search for the truth. In: JACKSON, John; LANGER, Máximo; TILlERS, Peter (eds.). Crime, Procedure and Evidence in a Comparative and International Context. Essays in honour of professor Mirjan Damaška. Oxford: Hart Publishing, 2008. p. 145-164. Com espefica referencia ao processo penal italiano, sobre o tema da verdade no processo; verdade processual; significado de "busca da verdade no processo penal"; juiz e verdade no enunciado fatual contida na imputação; verdade formal e verdade substancial; criticas sobre o conceito de "verdade"; analicamente, por todos: CAPRIOLI Francesco, Verità e giustificazione nel processo penale. Rivista italiana di diritto e procedura penale, 2013, fasc. 2, p. 608-625.

${ }^{22}$ ILLUMINATI, Giulio. The Frustrated Turn to Adversarial Procedure in Italy, op. cit., p. 572.

${ }^{23}$ ILLUMINATI, Giulio. El sistema acusatorio en Italia, op. cit., p. 153. Para um estudo manualístico detalhado sobre a fase da investigação preliminar italiana, ver: CAPRIOLI, Francesco. Indagini preliminari e udienza preliminare. In: CONSO, Giovanni; GREVI, Vittorio; BARGIS, Marta. Compendio di procedura penale. Padova: CEDAM, 2014. p. 512 ss. Em termos criticos sobre a
} 
Revista Eletrônica de Direito Processual - REDP. Volume 15. Janeiro a Junho de 2015 Periódico Semestral da Pós-Graduação Stricto Sensu em Direito Processual da UERJ. Patrono: José Carlos Barbosa Moreira. www.redp.com.br ISSN 1982-7636 PP 435-453

intitulado expediente do ministério público, conteria os atos investigatórios e teria como objetivo fundamentar a decisão do acusador acerca da imputação penal, restando inacessível ao julgador durante a fase processual, ${ }^{24}$ e o segundo, denominado expediente de debates, abrangeria as provas produzidas em contraditório diante do juiz durante o juízo oral. ${ }^{25}$ Por certo, foram previstas exceções, atos investigatórios que poderiam ser introduzidos nos autos de julgamento: provas não repetíveis, atos praticados em incidentes probatórios (antecipação da produção, atendendo às regras da oralidade e do contraditório), atos do corpo de delito e o histórico de antecedentes do acusado. ${ }^{26}$ Afora tais previsões, os atos da investigação somente poderiam ser referidos para contrastar com as declarações judiciais das testemunhas com o fim de desvelar manifesta contradição e, assim, abalar a sua credibilidade, ou seja, sem valor probatório efetivo. ${ }^{27}$ Em consequência de tal separação de fases, surge a proibição do "testemunho do ouvi dizer", característico do processo estadunidense no instituto do "hearsay", ${ }^{28}$ que, na Itália, se expressou especialmente pela vedação da oitiva na fase processual de policiais que conduziram as investigações sobre declarações anteriores de testemunhas. ${ }^{29}$

Após a promulgação do Código de Processo Penal de 1988, iniciou-se intrigante disputa entre os poderes legislativo e judiciário. Inicialmente, percebeu-se o fenômeno da inércia na interpretação das alterações, ${ }^{30}$ o que se expressava pela permanência nas atitudes dos juízes, que, por meio das exceções previstas legalmente, expandiram seus espaços para, por exemplo, violar a separação entre as fases investigatória e de

conformidade do processo penal italiano ao "giusto processo" imposto pela carta constitucional da Italia: FERRUA, Paolo. Il giusto processo, Bologna: Zanichelli, 2012.

${ }^{24}$ PANZAVOLTA, Michele. Reforms and Counter-Reforms in the Italian Struggle for an Accusatorial Criminal Law System, op. cit., p. 587.

${ }^{25}$ CHIAVARIO, Mario. O Processo Penal na Itália. In: DELMAS-MARTY, Mireille (dir.). Processo Penal e Direitos do Homem. Rumo à consciência europeia. Barueri: Manole, 2004. p. 47-48.

${ }^{26}$ PANZAVOLTA, Michele. Reforms and Counter-Reforms in the Italian Struggle for an Accusatorial Criminal Law System, op. cit., p. 588. Sobre a disciplina atualmente em vigor no codigo de processo penal italiano: ILLUMINATI, Giulio. Il giudizio. In: CONSO, Giovanni; GREVI, Vittorio; BARGIS, Marta. Compendio di procedura penale. Padova: CEDAM, 2014. p. 797 ss.

${ }^{27}$ ILLUMINATI, Giulio. El sistema acusatorio en Italia. In: BACHMAIER WINTER, Lorena (coord.). Proceso penal y sistemas acusatorios. Madrid: Marcial Pons, 2008. p. 153.

${ }^{28}$ Sobre isso, ver: BADARÓ, Gustavo Henrique. A utilização da hearsay witness na Corte Penal Internacional. Estudo sobre sua admissibilidade e valoração. Zeitschrift für Internationale Strafrechtsdogmatik, v. 04/2014, p. 177-188, 2014; MALAN, Diogo Rudge. Direito ao Confronto no Processo Penal. Rio de Janeiro: Lumen Juris, 2009. p. 92-106.

${ }^{29}$ ILLUMINATI, Giulio. The Frustrated Turn to Adversarial Procedure in Italy, op. cit., p. 572.

${ }^{30}$ Fenômeno semelhante ao descrito por Rubens Casara acerca do campo jurídico-penal brasileiro, sob a denominação de interpretação retrospectiva (CASARA, Rubens R. R. Interpretação Retrospectiva: sociedade brasileira e processo penal. Rio de Janeiro: Lumen Juris, 2004. p. 123-156). 
Revista Eletrônica de Direito Processual - REDP. Volume 15. Janeiro a Junho de 2015 Periódico Semestral da Pós-Graduação Stricto Sensu em Direito Processual da UERJ. Patrono: José Carlos Barbosa Moreira. www.redp.com.br ISSN 1982-7636 PP 435-453 julgamento, introduzindo indevidamente atos daquela nos autos de debate. ${ }^{31}$ Além dessa atitude dos julgadores em casos concretos, posteriormente, diante da reação negativa de parte dos atores do campo jurídico-penal e do cenário de forte pressão social para o recrudescimento do combate à criminalidade organizada (enfrentamento à máfia característico da época), a Corte Constitucional italiana adotou postura que relativizou as inovações trazidas pela nova legislação a partir de três marcantes decisões proferidas em 1992. ${ }^{32}$ Isso se deu com base no reconhecimento da inconstitucionalidade de regras de exclusão de provas, o que acarretou a aceitação de atos investigatórios para a fundamentação da sentença, com fundamento supostamente nos princípios da razoabilidade e da "não dispersão de provas", conforme o dever judicial de buscar a verdade: ${ }^{33}$ autorizou-se a oitiva de policiais acerca dos elementos coletados nas averiguações preliminares (decisão 24/1992), a utilização de depoimentos anteriores que contradigam as declarações judiciais (decisão 255/1992) ou de incriminações realizadas por corréus na fase investigativa e não reproduzidas judicialmente (decisão 254/1992).

Nesse sentido, Giulio Illuminati expressa sua perplexidade ao atestar que nos seus primeiros anos de vigência, o novo regramento de 1988 foi objeto de impugnações constitucionais muito mais numerosas do que o anterior, durante as décadas de sua aplicação, desde a promulgação na época fascista, perpassando inclusive o advento da Constituição Italiana dos anos $30 .{ }^{34}$ Por certo, a descrição dos embates ocasionados pela reforma integral do CPP italiano afirmam e desvelam por completo a influência determinante da postura dos atores do campo jurídico na concretização de uma alteração legislativa, ${ }^{35}$ pois seu regramento não foi traduzido para a prática. ${ }^{36} \mathrm{Ou}$ seja, trata-se de expressão de persistência de fator cultural, que contamina a atuação dos funcionários e a interpretação da norma com a permanência da tradição da busca da verdade por oficial imparcial. $^{37}$

Posteriormente, o parlamento aprovou nova tentativa de retomar o rumo ao modelo acusatório, reduzindo novamente a utilização de atos investigatórios na fase de

\footnotetext{
31 PANZAVOLTA, Michele. Reforms and Counter-Reforms in the Italian Struggle for an Accusatorial Criminal Law System, op. cit., p. 597.

${ }^{32}$ MARAFIOTI, Luca. Italian Criminal Procedure, op. cit., p. 85.

${ }^{33}$ ILLUMINATI, Giulio. The Frustrated Turn to Adversarial Procedure in Italy, op. cit., p. 574-575.

${ }^{34}$ ILLUMINATI, Giulio. El sistema acusatorio en Italia, op. cit., p. 149.

35 Sobre isso, ver: CARVALHO, Salo. O Papel dos Atores do Sistema Penal na Era do Punitivismo. O exemplo privilegiado da aplicação da pena. Rio de Janeiro: Lumen Juris, 2010. p. 59-111.

${ }^{36}$ MARAFIOTI, Luca. Italian Criminal Procedure: a system caught between two traditions, op. cit., p. 92.

${ }^{37}$ PANZAVOLTA, Michele. Reforms and Counter-Reforms in the Italian Struggle for an Accusatorial Criminal Law System, op. cit., p. 604.
} 
Revista Eletrônica de Direito Processual - REDP. Volume 15. Janeiro a Junho de 2015

Periódico Semestral da Pós-Graduação Stricto Sensu em Direito Processual da UERJ.

Patrono: José Carlos Barbosa Moreira. www.redp.com.br ISSN 1982-7636 PP 435-453

julgamento do processo e assegurando o direito ao confronto com o exame cruzado às testemunhas, ao proibir a utilização de declaração incriminatória de corréu durante a fase investigatória, se, no momento processual, ele exercer seu direito a não autoincriminação. Tal alteração enfrentou diretamente o posicionamento determinado anteriormente pelo Tribunal Constitucional, ocasionando novas impugnações, que findaram com a declaração da sua inconstitucionalidade (decisão 361/1998), sob a suposta violação aos princípios da razoabilidade e da igualdade. ${ }^{38}$ Portanto, evidenciouse o conflito entre legislativo e judiciário, de modo que a única alternativa para determinar a adoção da acusatoriedade nos termos propostos seria a consagração constitucional de seus contornos. ${ }^{39}$

Foi assim que, em 1999 com a "reforma do processo justo", ${ }^{40}$ introduziu-se na Constituição italiana as concepções do contraditório, da confrontação e da separação das fases investigatória e de julgamento, ao determinar que somente pode se considerar prova admissível a embasar a sentença aquilo produzido diante das partes, em situação de igualdade, e do juiz imparcial. ${ }^{41}$ Contudo, foram previstas três exceções, que autorizariam a utilização de provas produzidas fora da fase de debates e deveriam ser reguladas por lei: a concordância das partes, a prova de conduta ilícita e a impossibilidade da repetição diante do julgador. ${ }^{42}$ Então em 2001 alterou-se novamente o Código de Processo Penal, reestabelecendo as previsões julgadas inconstitucionais pela Corte Constitucional e, desse modo, determinando a separação entre as fases, a exclusão dos atos investigatórios, o direito ao confronto/exame-cruzado e a proibição

\footnotetext{
${ }^{38}$ Ibidem, p. 602.

39 “O parlamento e o judiciário estavam claramente em lados opostos em um conflito aberto, e o judiciária estava prevalecendo. Se tornou evidente que o único modo de frear o retrocesso a um sistema inquisitivo seria uma emenda constitucional." (PANZAVOLTA, Michele. Reforms and Counter-Reforms in the Italian Struggle for an Accusatorial Criminal Law System, op. cit., p. 602) (tradução livre).

40 “Constituição Italiana, artigo 111: 1. A jurisdição deve atuar conforme o princípio do devido processo legal. 2. Todo o processo deve se resolver através do contraditório entre as partes em posição de igualdade, diante de um juiz afastado e imparcial. A lei assegura o prazo razoável ao julgamento. 3. No processo penal, a lei assegura que: o acusado seja informado, na maior brevidade possível, da natureza e das razões da imputação criminal que lhe é feita; disponha do tempo e das condições adequadas para preparar sua defesa; ter a oportunidade de interrogar ou ter interrogada, diante do julgador, qualquer testemunha que o incrimine; dispor do direito de apontar testemunhas de defesa em condições de igualdade à acusação; assim como o direito de ser assistido por tradutor se não entender ou falar a língua utilizada no julgamento. 4. O processo penal é regulado pelo princípio do contraditório na formação da prova. A culpa do acusado não pode ser provada por declarações de alguém que, voluntariamente, se absteve de ser examinado pelo réu ou seu advogado. 5. A lei regulará os casos em que a prova poderá ser considerada mesmo se não produzida em contraditório, em razão do consentimento do acusado, de provada impossibilidade objetiva de repetição ou conduta ilícita." (tradução livre). Disponível em: http://www.governo.it/Governo/Costituzione/2_titolo4.html. Acesso em: 26 de março de 2015.

${ }^{41}$ MARAFIOTI, Luca. Italian Criminal Procedure: a system caught between two traditions, op. cit., p. 86.

${ }^{42}$ ILLUMINATI, Giulio. The Frustrated Turn to Adversarial Procedure in Italy, op. cit., p. 577.
} 
Revista Eletrônica de Direito Processual - REDP. Volume 15. Janeiro a Junho de 2015

Periódico Semestral da Pós-Graduação Stricto Sensu em Direito Processual da UERJ.

Patrono: José Carlos Barbosa Moreira. www.redp.com.br ISSN 1982-7636 PP 435-453

das declarações por "ouvi-dizer" (hearsay) de policiais. Diante da consagração

constitucional das regras acusatórias, a Corte Constitucional afirmou a constitucionalidade da reforma, admitindo a distinção entre as fases (decisão 439/2000), a vedação ao testemunho de policiais acerca de fatos da investigação (decisão 32/2002) e a utilização de atos investigatórios somente para fins de questionamento da credibilidade da testemunha, sem força probatória (decisão 36/2002). ${ }^{43}$

\section{A introdução de mecanismos de simplificação procedimental: o avanço da justiça criminal negocial no processo penal italiano.}

Além de consagrar o modelo acusatório, o Código de Processo Penal italiano de 1988 introduziu também mecanismos de simplificação processual, alternativas procedimentais visando à aceleração de julgamentos, ${ }^{44}$ sob o suposto argumento, apontado pela doutrina majoritária, ${ }^{45}$ de que tal desenho de justiça criminal acarretaria a morosidade na resposta estatal à delinquência, de modo que seriam imprescindíveis opções para um sentenciamento menos complexo. ${ }^{46}$ Cinco foram as alternativas procedimentais reguladas: 1) juízo diretíssimo; ${ }^{47}$ 2) juízo imediato; ${ }^{48}$ 3) procedimento

\footnotetext{
${ }^{43}$ PANZAVOLTA, Michele. Reforms and Counter-Reforms in the Italian Struggle for an Accusatorial Criminal Law System, op. cit., p. 615-616.

44 "O custo de julgamentos acusatórios é ainda maior na Itália em razão da sobrecarga processual das cortes italianas. Para que um sistema acusatório seja sustentável na Itália, nem todos os processos podem ir à julgamento ordinário, ou o sistema entraria em colapso. Os desenvolvedores do CPP de 1988 tinham noção desse risco e, para evitá-lo, criaram várias opções alternativas para resolver casos criminais." (PANZAVOLTA, Michele. Reforms and Counter-Reforms in the Italian Struggle for an Accusatorial Criminal Law System, op. cit., p. 594) (tradução livre).

${ }^{45}$ Apontando tal argumentação doutrinária: ILLUMINATI, Giulio. The Frustrated Turn to Adversarial Procedure in Italy, op. cit., p. 578. Além disso, há quem afirme que o principal objetivo do novo CPP, além de implementar a acusatoriedade, seria buscar a máxima celeridade do processo penal. Nesse sentido: DIEGO DÍEZ, Luis Alfredo de. Justicia Criminal Consensuada. Algunos modelos del derecho comparado en los EE. UU., Italia y Portugal. Valencia: Tirant lo Blanch, 1999. p. 124.

${ }^{46}$ Pode-se argumentar que a referida morosidade do modelo acusatório, em regra descrita a partir do exemplo adversarial estadunidense, não corresponde à descrição adequada de seus contornos, visto que tal lentidão não é ocasionada pelas suas características essenciais, mas por aspectos de cada sistema processual, como a sistemática do júri norte-americano ou a precariedade material (somada à expansão da intervenção penal) dos países periféricos.

${ }^{47}$ Conforme os artigos 449 a 452, o juízo diretíssimo ocorre quando o acusado é detido em flagrante (posteriormente convalidado judicialmente) ou quando confessa o delito em interrogatório, situação em que preza-se pela proximidade entre o fato e o julgamento, tornando-se desnecessária a fase intermediária do processo. Sobre isso, ver: MARAFIOTI, Luca. Italian Criminal Procedure, op. cit., p. 89.

${ }^{48}$ Com base nos artigos 453 a 458, o juízo imediato se dá na hipótese em que o lastro probatório no início do processo (formado a partir de sucinta investigação prévia) é suficiente para o seu julgamento, de modo que evita-se a fase intermediária (e sua audiência preliminar), passando-se diretamente à prolação da
} 
Revista Eletrônica de Direito Processual - REDP. Volume 15. Janeiro a Junho de 2015 Periódico Semestral da Pós-Graduação Stricto Sensu em Direito Processual da UERJ. Patrono: José Carlos Barbosa Moreira. www.redp.com.br ISSN 1982-7636 PP 435-453 por decreto penal; 4) juízo abreviado; e, 5) aplicação da pena por requisição das partes (conhecido como "patteggiamento"). Analisar-se-á os três últimos, em razão de sua proeminência em termos de justiça consensual, já que dependentes da manifestação de vontade do réu e do acordo com a acusação, entretanto, importante ressaltar que não se pretende desenvolver estudo exaustivo de cada instituto, mas expor pontos relevantes que possam contribuir à análise crítica do ordenamento brasileiro. Além das cinco alternativas originárias de 1988, em abril de 2014 adicionou-se a possibilidade da suspensão do processo condicionada à prova ("Sospensione del procedimento con messa alla prova"), regulada nos artigos 464-bis a 464-novies. ${ }^{49}$ Em termos breves, trata-se de mecanismo semelhante em finalidade à suspensão condicional do processo brasileira, podendo ser aplicado a delitos cominados com pena pecuniária ou detentiva não superior a quatro anos, conforme o artigo 464-bis, combinado com 186-bis. ${ }^{50}$

Conforme Giulio Illuminati, à época da reforma de 1988, pretendia-se que 20 a 40 por cento dos casos fossem resolvidos por meio dessas opções. ${ }^{51}$ Entretanto, com base em dados apontados por Máximo Langer, entre os anos de 1990 e 1998, o número de processos dispostos somente pelo patteggiamento (barganha) foi entre 17 e $21 \%$ nas cortes inferiores e 34 e $42 \%$ naquelas com jurisdição sobre delitos mais graves. ${ }^{52}$ Por certo, há clara distinção ao cenário estadunidense, em que mais de 90 por cento dos casos são concluídos por meio da plea bargaining, mas também é inegável a expansão dos mecanismos negociais de imposição de punições sem a comprovação da culpabilidade com o devido processo.

O procedimento por decreto penal, também conhecido como monitório, se caracteriza pela análise judicial acerca do processo sem a prévia citação do acusado, podendo impor condenação sem a manifestação das partes. ${ }^{53}$ Trata-se de instituto aplicável somente a delitos de menor gravidade, visto que a pena estabelecida limita-se

sentença. Sobre isso, remete-se a: FERNANDES, Antonio Scarance. Teoria Geral do Procedimento e O Procedimento no Processo Penal. São Paulo: RT, 2005. p. 218-220.

49 Trata-se de um rito consensual, com alegada finalidade despenalizadora, introduzido pela lei (67/2014), se não para resolver, ao menos para aliviar o problema endêmico de superpopulação carcerária italiana e da sobrecarga processual por meio da reformulação do sistema sancionatório, adicionando uma nova tipologia de punição: a prisão domiciliar. Para um estudo manualistico do novo instituto processual, ver: ORLANDI, Renzo. Procedimenti speciali. In: CONSO, Giovanni; GREVI, Vittorio; BARGIS, Marta. Compendio di procedura penale. Padova: CEDAM, 2014. p. 744 ss.

${ }^{50}$ Disponível em: http://www.altalex.com/index.php?idnot=67092. Acesso em: 26 de março de 2015.

${ }^{51}$ ILLUMINATI, Giulio. The Frustrated Turn to Adversarial Procedure in Italy, op. cit., p. 579.

${ }^{52}$ LANGER, Máximo. From Legal Transplants to Legal Translations, op. cit., p. 67.

53 FERNANDES, Antonio Scarance. Teoria Geral do Procedimento e O Procedimento no Processo Penal, op. cit., p. 210. 
Revista Eletrônica de Direito Processual - REDP. Volume 15. Janeiro a Junho de 2015 Periódico Semestral da Pós-Graduação Stricto Sensu em Direito Processual da UERJ. Patrono: José Carlos Barbosa Moreira. www.redp.com.br ISSN 1982-7636 PP 435-453

à multa pecuniária. Após determinar a punição, em regra com benefício de redução (até a metade), cita-se o réu, que pode aceitá-la ou se opor, situação em que ocorre o início do julgamento ordinário do caso e se torna ineficaz a condenação anterior. ${ }^{54}$ Em relação ao juízo abreviado, inicialmente, conforme sua versão original regulada pelo CPP de 1988, era resultado de acordo entre acusação e defesa, que consentiriam em acelerar o julgamento, possibilitando o encerramento do caso no momento da audiência preliminar (fase intermediária), ou seja, decidir-se-ia conforme o estado do processo após as investigações. Trata-se de uma barganha sobre o procedimento, que era cabível a qualquer delito e beneficiava o réu com uma redução de um terço na punição. ${ }^{55}$ Entretanto, essa opção alternativa tinha pouca utilização prática, além de ter sido questionada perante a Corte Constitucional italiana. Em razão disso, tal procedimento foi alterado em 1999, dispensando-se a manifestação positiva do acusador público (sendo assim de iniciativa exclusiva da defesa) e, em caso de insuficiência dos atos investigatórios, autorizando a produção probatória de ofício ou segundo solicitação das partes. Manteve-se, contudo, seus traços essenciais, já que sua utilização resulta no julgamento conforme o estado dos autos com base na investigação preliminar. ${ }^{56}$

Em que pese tais importantes inovações no cenário de uma cultura processual alternativa simplificadora, ${ }^{57}$ certamente o instituto que acarretou maiores tensões ao sistema italiano de traços continentais foi a aplicação da pena por requisição das partes ou "patteggiamento". Tal experiência adveio de tentativa precursora, que em 1981 introduziu com a lei 689 a possibilidade de imposição de uma pena diversa da prisão com base em pedido da defesa consentido pela acusação, ${ }^{58}$ ou seja, tratava-se de mecanismo limitado e de pouca utilização. ${ }^{59} \mathrm{O}$ novo patteggiamento implementou-se com o CPP de 1988, revogando a referida legislação de 1981, sendo cabível originariamente a delitos cuja sentença final se limitasse a até dois anos, computada a

\footnotetext{
54 PANZAVOLTA, Michele. Reforms and Counter-Reforms in the Italian Struggle for an Accusatorial Criminal Law System, op. cit., p. 595-596.

55 FERNANDES, Antonio Scarance. Teoria Geral do Procedimento e O Procedimento no Processo Penal, op. cit., p. 202.

56 VAN CLEAVE, Rachel A. An offer you can’t refuse?, op. cit., p. 450-452.

57 FERNANDES, Antonio Scarance. Teoria Geral do Procedimento e O Procedimento no Processo Penal, op. cit., p. 179-191.

${ }^{58}$ DIEGO DÍEZ, Luis Alfredo de. Justicia Criminal Consensuada., op. cit., p. 126-131.

59 Conforme Rachel Van Cleave, o "velho patteggiamento" foi uma tentativa significante no sentido de resolução de casos penais sem julgamento, mas foi pouco utilizado, pois os acusados preferiam optar pelos procedimentos ordinários com a esperança de absolvição ou de suspensão da pena (vedada no caso de aplicação do dispositivo de 1981) (VAN CLEAVE, Rachel A. An offer you can’t refuse?, op. cit., p. 439).
} 
Revista Eletrônica de Direito Processual - REDP. Volume 15. Janeiro a Junho de 2015 Periódico Semestral da Pós-Graduação Stricto Sensu em Direito Processual da UERJ. Patrono: José Carlos Barbosa Moreira. www.redp.com.br ISSN 1982-7636 PP 435-453

redução de um terço em benefício do réu, mas, posteriormente, em 2003, expandiu-se para o limite de cinco anos, também após a diminuição. Por certo, evidencia-se a semelhança ao plea bargaining de origem na common law, entretanto, em sua tradução aos sistemas continentais, uma de suas principais diferenciações é o controle judicial mais atuante acerca da regularidade e do cabimento do acordo. ${ }^{60}$

A análise do instituto da aplicação da pena por requisição das partes propicia importantes contribuições à análise crítica dos mecanismos negociais em sistemas processuais continentais. Primeiramente, ponto fulcral do exemplo italiano é a necessidade de motivação da decisão do Ministério Público acerca do cabimento do patteggiamento e as consequências da recusa ilegítima. Em contraste com o modelo estadunidense, cuja ampla discricionariedade do promotor impede amplo controle acerca da barganha, na Itália os motivos da recusa são verificados pelo juiz, que, se entendê-la injustificada, assegurará a redução solicitada pelo acusado, mesmo após o transcorrer de todo o procedimento ordinário, ${ }^{61}$ consagrando assim o acordo como direito subjetivo do réu. Além disso, ao considerar a proposta de barganha, o julgador pode inclusive absolver o acusado, mesmo diante da conformidade defensiva com a imposição da pena. Ou seja, não se trata de um reconhecimento de culpabilidade ao estilo do guilty plea norte-americano, que acarreta automaticamente a condenação do imputado, mas um requerimento ao juiz para que analise o caso e verifique a adequação do acordo proposto. Ademais, a confirmação da punição em razão do acordo, em regra, não traz efeitos civis ou administrativos, limitando, assim, as consequências da confissão. ${ }^{62}$ Por fim, marcante posicionamento da Corte Constitucional italiana (decisão 186/1992) determinou a perda da imparcialidade do julgador que rejeita a proposta de barganha, em razão do indevido contato prévio com o mérito do caso.

A constitucionalidade do instituto patteggiamento foi analisada pela Corte Constitucional da Itália em diversos aspectos na decisão 313 de $1990 .{ }^{63} \mathrm{O}$ principal ponto assentado foi a possibilidade da averiguação pelo juiz acerca da

\footnotetext{
${ }^{60}$ Aponta-se que, em razão da atenção aos princípios da legalidade e da obrigatoriedade - característicos dos modelos continentais - a barganha tem seus contornos verificados pelo judiciário, limitando, assim, a discricionariedade do acusador público. Sobre isso, ver: ILLUMINATI, Giulio. El sistema acusatorio en Italia, op. cit., p. 160.

${ }^{61}$ VAN CLEAVE, Rachel A. An offer you can't refuse?, op. cit., p. 449; FORMMANN, Maike. Regulating Plea-Bargaining in Germany: Can the Italian. Approach serve as a Model to Guarantee the Impartiality of. German Judges? Hanse Law Review, v.5, n. 1, p. 197-220, 2009. p. 214.

${ }^{62}$ LANGER, Máximo. From Legal Transplants to Legal Translations, op. cit., p. 65.

${ }^{63}$ Disponível em: http://www.giurcost.org/decisioni/1990/0313s-90.html. Acesso em: 26 de março de 2015.
} 
Revista Eletrônica de Direito Processual - REDP. Volume 15. Janeiro a Junho de 2015

Periódico Semestral da Pós-Graduação Stricto Sensu em Direito Processual da UERJ.

Patrono: José Carlos Barbosa Moreira. www.redp.com.br ISSN 1982-7636 PP 435-453

proporcionalidade da pena proposta no acordo, especificamente na questão de sua adequação aos valores reeducadores da punição (prevenção especial positiva, constitucionalmente fixada no artigo 27.3 da Constituição da Itália), ${ }^{64}$ de modo que o julgador pode rejeitar a barganha se entender a pena sugerida inadequada para tais fins, seja por excesso ou por insuficiência, não estando, portanto, limitado à mera análise dos requisitos formais. ${ }^{65}$ Entretanto, o referido tribunal afastou qualquer ilegitimidade do instituto negocial em relação aos princípios da sujeição do juiz unicamente à lei (sob o argumento de que os casos estão legalmente regulados e o juiz pode analisar a proposta materialmente e formalmente), da exclusividade jurisdicional na determinação da pena (afirmando que o juiz exerce sim a função jurisdicional, pois as partes não poderiam resolver o caso sem sua manifestação), da necessidade de motivação das decisões (pois o juiz deve fundamentar sua análise material e formal sobre a proposta de acordo), da presunção de inocência (já que, conforme o julgado, ao requerer a aplicação da pena, o acusado renuncia à faculdade de contestar a acusação, mas isso não significa violação à presunção de inocência) ou dos direitos à liberdade (porque a punição é imposta conforme manifestação judicial) e à defesa (visto que a aceitação do réu à imposição de pena se dá no âmbito do exercício do direito de defesa ao buscar situação menos gravosa). ${ }^{66}$

Contudo, existem fundadas críticas doutrinárias às possibilidades de barganha entre acusação e defesa, especialmente em razão do retrocesso inquisitivo ocasionado por sua prática, que acaba desvirtuando o modelo acusatório constitucionalmente traçado. ${ }^{67}$ Além disso, há quem aponte a incontornável tensão entre tal mecanismo transplantado de modelo processual de cultura distinta e o sistema italiano, de origem

\footnotetext{
64 "A pena não pode consistir em tratamento contrário ao senso de humanidade e deve tender à reeducação do condenado". Disponível em: http://www.governo.it/Governo/Costituzione/1_titolo1.html. Acesso em: 26 de março de 2015 (tradução livre).

${ }^{65}$ VAN CLEAVE, Rachel A. An offer you can't refuse?, op. cit., p. 446-447.

${ }^{66}$ DIEGO DÍEZ, Luis Alfredo de. Justicia Criminal Consensuada, op. cit., p. 159-167; FORMMANN, Maike. Regulating Plea-Bargaining in Germany, op. cit., p. 210-217.

67 "Muitos doutrinadores italianos não concordam com a tendência legislativa. Eles pensam que ela reintroduz o estilo inquisitorial de processo penal, do qual a Itália pretendia se afastar. A crítica dos procedimentos alternativos como um sistema inquisitorial oculto existe desde a data de promulgação do Código de 1988. O questionamento da atual expansão dos procedimentos especiais se fundamenta no correto pensamento de que a existência de um juízo acusatório não é suficiente para tornar o sistema acusatório. Não só o potencial para um julgamento acusatório deve ser garantido, mas também sua efetividade. Assim, os procedimentos alternativos, como o juízo abreviado, não devem ter um papel mais importante do que o julgamento acusatório na resolução dos casos criminais. Se mais processos são resolvidos de um modo inquisitorial, o sistema acusatório se torna essencialmente inquisitorial." (PANZAVOLTA, Michele. Reforms and Counter-Reforms in the Italian Struggle for an Accusatorial Criminal Law System, op. cit., p. 621-622) (tradução livre).
} 
Revista Eletrônica de Direito Processual - REDP. Volume 15. Janeiro a Junho de 2015 Periódico Semestral da Pós-Graduação Stricto Sensu em Direito Processual da UERJ. Patrono: José Carlos Barbosa Moreira. www.redp.com.br ISSN 1982-7636 PP 435-453

continental, pois, conforme Mirjan Damaška, em que pese as tentativas dos especialistas italianos de conciliar os mecanismos consensuais com a tradição de seu ordenamento, o patteggiamento continua sendo percebido como um corpo alienígena, estranho ao campo jurídico-penal nacional: "retirada de seu habitat natural, desorientada no seu novo entorno institucional, a barganha resta desprendida de seu ambiente, como uma consequência subitamente sem causa". ${ }^{68}$

\section{Problematizações e debates atuais acerca da barganha no processo penal italiano.}

Atualmente, pode-se afirmar que permanece a ser analisada a hipótese na qual o juiz do patteggiamento se encontre diante a um lastro probatório insuficiente ou contraditório. ${ }^{69}$ Assim, é este o perfil da disciplina atual do patteggiamento que revela os maiores pontos críticos. ${ }^{70}$

Ainda são inúmeras as perplexidades e críticas no atual debate cientifico italiano acerca da ideia de que o imputado possa, com esse rito, renunciar às regras de julgamento do in dubio pro reo. Admitir que uma verdade negociada possa justificar um erro judiciário, de fato, significa em um certo modo reconhecer o poder de dispor da liberdade da pessoa e da função cognitiva do processo. E isso parece ser contrário ao principio segundo o qual a decisão deve ser o quanto mais possível livre de erro, visto que no sistema penal italiano não cabe espaço para uma visão da justiça penal somente como resolução de uma negociação entre interesses privados. ${ }^{71}$

\footnotetext{
${ }^{68}$ DAMAŠKA, Mirjan. Negotiated Justice in International Criminal Courts. In: THAMAN, Stephen C. (ed.). World Plea Bargaining. Consensual Procedures and the Avoidance of the Full Criminal Trial. Durham: Carolina Academic Press, 2010. p. 89 (tradução livre).

69 Sobre o assunto, amplamente, SCOMPARIN, Laura. Il proscioglimento immediato nel sistema processuale penale. Torino: Giappichelli, 2008. p. 201 ss.

${ }^{70}$ Como revela, por exemplo, GIALUZ, Mitja. La virata delle sezioni unite in tema di patteggiamento e revoca della sospensione condizionale: verso l'abbandono dell'orientamento anticognitivo? Rivista italiana di diritto e processo penale, 2007, p. 373. Contudo, cumpre citar que falta no CPP italiano a previsão explicita da possibilidade de uma rejeição do pedido de pattegiamento por motivos interligados a falta de alcance processual do standard de verossimilhança do pedido em relação ao fato principal.

${ }^{71}$ DE CARO, Agostino. Le linee politiche della legge n. 134 del 2003. Principi fondamentali e nuovo "patteggiamento". In: DE CARO, Agostino. Patteggiamento allargato e sistema penale. Milano: Giuffré, 2004.
} 
Revista Eletrônica de Direito Processual - REDP. Volume 15. Janeiro a Junho de 2015 Periódico Semestral da Pós-Graduação Stricto Sensu em Direito Processual da UERJ. Patrono: José Carlos Barbosa Moreira. www.redp.com.br ISSN 1982-7636 PP 435-453

Não obstante, a posição da jurisprudencia italiana é consolidada: ${ }^{72}$ a falta, a contradição e a insuficiência da prova pode acarretar consequências somente aos fins da fase processual do processo, quando o julgador é chamado a pronunciar a absolvisão do réu conforme o artigo 530.2 do CPP italiano. Antes dessa fase processual e nos procedimentos deflativos de tipo negocial, inexiste tal possibilidade, porque não há correspondências às causas explicitamente indicadas no artigo 129 do CPP italiano, sobre a imediata declaração de não punibilidade do imputado, encontrando um obstáculo na fase investigatória do procedimento.

Percebe-se que é evidente a confusão acerca de tais regramentos procedimentais. Por isto é desejável, sobre tudo depois das controvérsias sobre a natureza da sentença de patteggiamento, que o problema seja definido em modo mais adequado, de preferencia, com uma intervenção legislativa que oportunamente clarifique os contornos da questão. As alternativas poderiam ser várias. Uma delas seria reconhecer explicitamente ao juiz o poder de non liquet, admitindo a possibilidade ao julgador de devolver os autos ao ministério público (em forma análoga ao caso em que a pena seja julgada incongruente); ou, pelo contrário, atribuir especificamente ao juiz o poder de absolver o imputado com base nas regras do artigo 530.2 CPP italiano.

Outras soluções poderiam, por exemplo, favorecer a realização do grau de plenitudine do material probatório necessário para condenar. Em particular, partindo da ideia segundo a qual no pateggiamento também se deve aplicar a regra do in dubio pro reo, diante de um lastro probatório insuficiente, poderia se reconhecer ao juiz a faculdade de se abster de decidir o pedido de patteggiamento, dando possibilidade para o exercício do direito de prova das partes. Esse modelo ressaltaria o papel de garantia da jurisdição.

\section{Considerações Finais}

Diante do exposto, percebe-se que o exemplo italiano é profícuo ao desvelar a resistência dos atores do campo jurídico-criminal diante de tentativas de avanço em vistas de uma adequação acusatória do processo penal, fundamentalmente caracterizada

\footnotetext{
${ }^{72}$ Neste sentido, ver, por exempo, Cassazione Sezioni Unite, 25 de outubro de 1995, Cardoni e outros, em Rivista italiana di diritto e processo penale, 1996, pag. 1157, com comentario critico de MERCURI, B., Le Sezioni Unite intervengono sull'ambito applicativo della regola di giudizio ex art. 530 comma 2 c.p.p.
} 
Revista Eletrônica de Direito Processual - REDP. Volume 15. Janeiro a Junho de 2015 Periódico Semestral da Pós-Graduação Stricto Sensu em Direito Processual da UERJ. Patrono: José Carlos Barbosa Moreira. www.redp.com.br ISSN 1982-7636 PP 435-453

pela estrita separação entre os elementos produzidos durante investigações preliminares e as provas originadas em respeito ao contraditório na fase processual. Esse é o ponto marcante da descrição introdutória acerca das modificações ocasionadas na justiça criminal italiana nos anos 90 .

Com relação aos mecanismos negociais e procedimentos alternativos, apontou-se que o questionamento crítico doutrinário é constante e cientificamente fundamentando tendo-se em vista o respeito às premissas de um processo penal democrático. Contudo, alguns pontos podem ser ressaltados como possíveis contribuições ao debate da compatibilização da barganha aos sistemas continentais (se isso for realmente possível...), especialmente diante das previsões do PLS 156/09 (em seu criticável "procedimento sumário"): 1) se atendidos no caso concreto os requisitos legais para a admissibilidade do acordo, configura-se um direito subjetivo do acusado, que não pode ser violado por discricionariedade do acusador ou por motivos que não encontrem respaldo na texto legal; 2) desse modo, a solução italiana se mostra pertinente: em caso de injustificada negativa do representante do Ministério Público, o processo deve seguir seu normal decorrer e, em caso de condenação, o juiz reduzirá a sanção nos termos previstos em lei, ainda que após o transcorrer de todo o procedimento ordinário; 3 ) portanto, o posicionamento do acusador acerca da admissibilidade do acordo deve ser estritamente motivado em respeito à legalidade; 4) ao considerar a proposta de barganha, o julgador pode absolver o acusado, mesmo diante da conformidade defensiva, de modo que a confissão negociada não é considerada uma prova inquestionável; e, 5) o juiz que recusa uma proposta de acordo e determina o prosseguimento do julgamento ordinário tem sua imparcialidade fragilizada em razão do indevido contato prévio com o mérito do caso, de modo a impor a remessa dos autos para outro julgador.

De qualquer modo, cumpre ressaltar que a introdução de mecanismos negociais de modo generalizado (além do espaço constitucionalmente traçado da transação penal nas infrações de menor potencial ofensivo), autorizando a imposição de sanções sem o respeito às regras do devido processo, deve ser criticada e rechaçada no campo jurídicocriminal pátrio, pois acarreta inevitáveis violações às premissas do processo penal 
Revista Eletrônica de Direito Processual - REDP. Volume 15. Janeiro a Junho de 2015 Periódico Semestral da Pós-Graduação Stricto Sensu em Direito Processual da UERJ. Patrono: José Carlos Barbosa Moreira. www.redp.com.br ISSN 1982-7636 PP 435-453 democrático ao distorcer por completo a sua essência fundamental: ser instrumento de limitação do poder punitivo estatal. ${ }^{73}$

\section{REFERÊNCIAS BIBLIOGRÁFICAS}

AMODIO, Enio, Vitórias e derrotas da cultura dos juristas na elaboração do novo código de processo penal. Revista Brasileira de Ciências Criminais, São Paulo, ano 7, n. 25 , p. 09-22, jan./mar. 1999.

ARMENTA DEU, Teresa. Sistemas procesales penales. La justicia penal en Europa y América. Madrid: Marcial Pons, 2012.

BADARÓ, Gustavo Henrique. A utilização da hearsay witness na Corte Penal Internacional. Estudo sobre sua admissibilidade e valoração. Zeitschrift für Internationale Strafrechtsdogmatik, v. 04/2014, p. 177-188, 2014.

CAPRIOLI, Francesco. Verità e giustificazione nel processo penale. Rivista italiana di diritto e procedura penale, 2013, fasc. 2, p. 608-625.

. Indagini preliminari e udienza preliminare. In: CONSO, Giovanni;

GREVI, Vittorio; BARGIS, Marta. Compendio di procedura penale. Padova: CEDAM, 2014.

CASARA, Rubens R. R. Interpretação Retrospectiva: sociedade brasileira e processo penal. Rio de Janeiro: Lumen Juris, 2004.

CARVAlHO, Salo. O Papel dos Atores do Sistema Penal na Era do Punitivismo. O exemplo privilegiado da aplicação da pena. Rio de Janeiro: Lumen Juris, 2010.

CHIAVARIO, Mario. O Processo Penal na Itália. In: DELMAS-MARTY, Mireille (dir.). Processo Penal e Direitos do Homem. Rumo à consciência europeia. Barueri: Manole, 2004.

DAMAŠKA, Mirjan. Negotiated Justice in International Criminal Courts. In: THAMAN, Stephen C. (ed.). World Plea Bargaining. Consensual Procedures and the Avoidance of the Full Criminal Trial. Durham: Carolina Academic Press, 2010.

\footnotetext{
73 Acerca das críticas ao modelo negocial, ver: VASCONCELLOS, Vinicius G. Barganha e Justiça Criminal Negocial, op. cit., p. 259-321.
} 
Revista Eletrônica de Direito Processual - REDP. Volume 15. Janeiro a Junho de 2015 Periódico Semestral da Pós-Graduação Stricto Sensu em Direito Processual da UERJ. Patrono: José Carlos Barbosa Moreira. www.redp.com.br ISSN 1982-7636 PP 435-453 DE CARO, Agostino. Le linee politiche della legge n. 134 del 2003. Principi fondamentali e nuovo "patteggiamento". In: DE CARO, Agostino. Patteggiamento allargato e sistema penale. Milano: Giuffré, 2004.

DIEGO DÍEZ, Luis Alfredo de. Justicia Criminal Consensuada. Algunos modelos del derecho comparado en los EE. UU., Italia y Portugal. Valencia: Tirant lo Blanch, 1999. FERNANDES, Antonio Scarance. Teoria Geral do Procedimento e O Procedimento no Processo Penal. São Paulo: RT, 2005.

FERRAJOLI, Luigi. Direito e Razão. Teoria do Garantismo Penal. $4^{\text {a }}$ ed. São Paulo: RT, 2014.

FERRUA, Paolo. La giustizia negoziata nella crisi della funzione cognitiva del processo penale. In: La giustizia contrattata. Dalla bottega al mercato globale. Napoli: Esi, 1998. Il giusto processo, Bologna: Zanichelli, 2012.

FORMMANN, Maike. Regulating Plea-Bargaining in Germany: Can the Italian. Approach serve as a Model to Guarantee the Impartiality of. German Judges? Hanse Law Review, v.5, n. 1, p. 197-220, 2009.

GIALUZ, Mitja. La virata delle sezioni unite in tema di patteggiamento e revoca della sospensione condizionale: verso l'abbandono dell'orientamento anticognitivo? Rivista italiana di diritto e processo penale, 2007.

GRANDE, Elisabetta. Dances of Criminal Justice: thoughts on systemic diferences and the search for the truth. In: JACKSON, John; LANGER, Máximo; TILLERS, Peter (eds.). Crime, Procedure and Evidence in a Comparative and International Context. Essays in honour of professor Mirjan Damaška. Oxford: Hart Publishing, 2008.

ILLUMINATI, Giulio. The Frustrated Turn to Adversarial Procedure in Italy (Italian Criminal Procedure Code of 1988). Washington University Global Studies Law Review, vol. 4, p. 567-581, 2005.

. El sistema acusatorio en Italia. In: BACHMAIER WINTER, Lorena (coord.). Proceso penal y sistemas acusatorios. Madrid: Marcial Pons, 2008.

. Il giudizio,. In: CONSO, Giovanni; GREVI, Vittorio; BARGIS, Marta. Compendio di procedura penale. Padova: CEDAM, 2014. p. 797 ss.

LANGER, Máximo. From Legal Transplants to Legal Translations: The Globalization of Plea Bargaining and the Americanization Thesis in Criminal Procedure. In: THAMAN, Stephen C. (ed.). World Plea Bargaining. Consensual Procedures and the Avoidance of the Full Criminal Trial. Durham: Carolina Academic Press, 2010. 
Revista Eletrônica de Direito Processual - REDP. Volume 15. Janeiro a Junho de 2015 Periódico Semestral da Pós-Graduação Stricto Sensu em Direito Processual da UERJ. Patrono: José Carlos Barbosa Moreira. www.redp.com.br ISSN 1982-7636 PP 435-453 MALAN, Diogo Rudge. Direito ao Confronto no Processo Penal. Rio de Janeiro: Lumen Juris, 2009.

MARAFIOTI, Luca. Italian Criminal Procedure: a system caught between two traditions. In: JACKSON, John; LANGER, Máximo; TILLERS, Peter (eds.). Crime, Procedure and Evidence in a Comparative and International Context. Essays in honour of professor Mirjan Damaška. Oxford: Hart Publishing, 2008.

ORLANDI, Renzo. Procedimenti speciali. In: CONSO, Giovanni; GREVI, Vittorio; BARGIS, Marta. Compendio di procedura penale. Padova: CEDAM, 2014. p. 744 ss.

PANZAVOLTA, Michele. Reforms and Counter-Reforms in the Italian Struggle for an Accusatorial Criminal Law System. North Carolina Journal of International Law \& Commercial Regulation, vol. 30, n. 3, p. 577-623, 2005.

SCOMPARIN, Laura. Il proscioglimento immediato nel sistema processuale penale. Torino: Giappichelli, 2008.

VAN CLEAVE, Rachel A. An offer you can't refuse? Punishment without trial in Italy and the United States: the search for truth and an efficient criminal justice system. Emory International Law Review, v. 11, p. 419-469, 1997.

VASCONCELLOS, Vinicius G. Barganha e Justiça Criminal Negocial: análise das tendências de expansão dos espaços de consenso no processo penal brasileiro. 2014. Dissertação (Mestrado em Ciências Criminais) - Faculdade de Direito, Pontifícia Universidade Católica do Rio Grande do Sul, Porto Alegre. 